\title{
O Produto Verde é Sempre “Verde"? Uma Análise do Bloco Cerâmico a partir do Ecodesign ${ }^{1}$
}

\section{Where is The Green Product "Green"? An Analysis of the ceramic block from the Ecodesign}

\author{
Isabel Joselita Barbosa da Rocha Alves, MSc. \\ Professora do Departamento de Contabilidade da Universidade Estadual da Paraíba \\ Rua Baraúnas, 351 - Bairro Universitário - Campina Grande-PB, CEP 58429-500, Campina Grande, PB. \\ Fone/Fax: 83 3315.3300, e-mail: beljrocha@ibest.com.br
}

\author{
Lúcia Santana de Freitas, Dra . \\ Professora da Unidade Acadêmica de Administração e Contabilidade da UFCG e do Programa de Pós-Graduação \\ em Recursos Naturais - PPGRN/UFCG \\ Rua, Aprígio Veloso, 882, Bairro Universitário, CEP: 58.429-900, Campina Grande, PB. \\ Fone: (83) 2101-1000, e-mail: lucia.sdefreitas@gmail.com
}

\section{RESUMO}

Atualmente, face aos problemas ambientais causados pela produção e consumo exacerbados de materiais e energia e dos resíduos gerados, a atividade de desenhar produtos verdes é fundamental para o desenvolvimento sustentável. Este estudo objetivou analisar através do uso combinado das ferramentas de ecodesign: Ecodesign PILOT e Teia das Estratégias do Ecodesign (TEE) se um produto concebido como verde é de fato "verde". Teoricamente centrou-se na discussão de ecodesign, produtos verdes e nas ferramentas de ecodesign utilizadas, as quais contemplam todas as etapas do ciclo de vida do produto. Trata-se de um estudo de caso, cujo objeto foi o Bloco Cerâmico Econômico. Foram utilizadas entrevista semiestruturada e dois questionários elaborados a partir das ferramentas citadas. Como resultados, o Ecodesign PILOT classificou o produto como Tipo B, ou seja, a fase de fabricação apresenta maior carga ambiental. Quanto à TEE, a otimização pós-uso do produto foi considerada de alta prioridade, isto se dá pelo fato da empresa não manter uma política de reciclagem do produto ao final de sua vida útil, dada a impossibilidade de identificar o responsável pelos resíduos gerados. Os demais resultados das duas ferramentas apresentaram-se convergentes, mostrando que o produto de fato pode ser considerado como verde.

Palavras-chave: Produto verde. Ecodesign PILOT. Teia das Estratégias do Ecodesign.

\begin{abstract}
Nowadays, face to the environmental problems caused by the production and consumption exacerbated of materials and energy and of the generated residues, the activity of drawing green products is essential for the sustainable development. This study aimed at to analyze through the combined use of the ecodesign tools: Ecodesign PILOT and Web Strategies of the Ecodesign (TEE) if a product designed as green it is in fact "green." Theoretically focused on discussion of ecodesign, green products and in the tools of used ecodesign, which contemplate all the stages of the cycle of life of the product. It is a case study, whose object was the Economic Ceramic Block. We used a semistructured interview and two questionnaires elaborated developed from the mentioned tools. As results, the Ecodesign PILOT classified the product as Tipo B, in other words, the production phase presents larger environmental load. With relationship to TEE, the optimization of post-use of the product was considered of high priority, this happens because of the company does not maintain a recycling politics of the product at the end of your useful life, given the impossibility of identifying the responsible for the generated residues. The other results of the two tools came convergent, showing that the product in fact can be considered as green.
\end{abstract}

Keywords: Green Product. Ecodesign PILOT. Web Strategies of Ecodesign.

1 Artigo recebido em 26.01.2013. Avaliado pelos pares em 21.02.2013. Reformulado em 23.02.2013. Aceito para publicação em 23.02.2013. Recomendado para publicação por José Ribamar Marques de Carvalho (Editor Científico). Publicado em 01.04.2013. 


\section{INTRODUÇÃo}

Os problemas ambientais provocados pelos seres humanos decorrem do uso abusivo dos recursos naturais para produção de bens e serviços e dos despejos de materiais e energia que são jogados no meio ambiente, de sistemas de produção e consumo destrutivo sem nenhuma preocupação com equilíbrio da relação homemnatureza.

Um dos mais consideráveis problemas diz respeito à necessidade de otimizar a integração de atividades de desenvolvimento de produtos em conjunto com os impactos ambientais do produto e requisitos da legislação ambiental (HEPPERLE et $a l, 2010)$.

O desenvolvimento de produtos e design usando uma perspectiva de ciclo de vida tem despertado o interesse tanto das empresas quanto das autoridades. Do ponto de vista da empresa o interesse vem da esperança de alcançar vantagens competitivas e das autoridades pela possibilidade potencial de diminuir os impactos ambientais e sobre a saúde e contribuição para o consumo sustentável (JÖNBRINK \& MELIN, 2008).

A atividade de desenhar produtos verdes é necessária ao desenvolvimento sustentável, uma vez que se pensará em menor uso de materiais e energia, menos resíduos gerados e menos poluição e degradação, além de benefícios no que se refere à saúde e a segurança dos seres humanos. A solução dos problemas ambientais, ou sua minimização, exige uma nova atitude dos gestores que devem passar a considerar o meio ambiente em suas decisões e adotar modelos de gestão e tecnologias que reduzam os impactos ambientais e contribuam para ampliar a capacidade de suporte do planeta (BARBIERI, 2007).

Fargnoli e Kimura (2006) consideram que a abordagem para o desenvolvimento de produtos verdes, independente do grau de inovação e das tarefas que o designer tem de executar, pode ser considerada como uma atividade de designer que envolve: demandas e expectativas dos clientes, necessidades da empresa, requisitos de lei, regulamentos e necessidades da sociedade.

Neste sentido, o ecodesign apresenta-se como uma das mais difundidas e eficazes abordagens para desenvolvimento de produtos verdes, que visa dar resposta para o mundo industrial em relação às pressões ambientais e sociais (HEPPERLE et $a l, 2010)$. Inúmeras e diferentes ferramentas de ecodesign estão disponíveis para que as empresas possam escolher a que melhor se adapta as suas particularidades, dentre essas se destacam o Ecodesign PILOT e a Teia de Estratégias do Ecodesign (TEE).

$\mathrm{O}$ uso de diferentes tipos de ferramentas de ecodesign pode destacar potencial problema ambiental e facilitar a escolha sobre aspectos ambientais diversos. Algumas ferramentas podem ser complementadas com outras (BYGGETH \& HOCHSCHORNER, 2006), pois o uso de uma única ferramenta não é suficiente para 
melhorar a sustentabilidade do produto eficazmente, assim o uso combinado de várias ferramentas deve ser previsto (FARGNOLI \& SAKAO, 2008).

Diante do exposto, considerando a necessidade da inclusão da variável ambiental no desenho de produtos e que atualmente há um grande número de empresas que procura apresentar seus produtos como produtos verdes, o presente estudo define o seguinte problema de pesquisa: os produtos concebidos como verdes são realmente verdes? Na busca de resposta para a questão de pesquisa formulada o presente estudo teve como objetivo analisar através do uso combinado das ferramentas de ecodesign, Ecodesign PILOT e TEE, se um produto concebido como verde é de fato "verde".

Dessa forma, o artigo é composto por cinco seções. Após essa introdução, na seção 2 é apresentada a fundamentação teórica, com descrição sobre elementos necessários à parte prática do estudo: ecodesign, produto verde, Ecodesign PILOT e Teia das Estratégias do Ecodesign. Na Seção 3, é descrita a metodologia adotada. A seção 4 apresenta os resultados e discussões da pesquisa, e concluindo, a seção 5 traz as considerações finais.

\section{FUNDAMENTAÇÃO TEÓRICA}

\subsection{Ecodesign}

O ecodesign é uma ferramenta de gestão ambiental centrada na fase de concepção dos produtos e dos seus respectivos processos de produção, distribuição e utilização (BARBIERI, 2007). Apesar do ecodesign ser também aplicado aos processos e serviços, é mais comum sua aplicação ao produto, de modo que a empresa busca apresentar ao cliente além de atributos ambientais, funcionalidade, qualidade, eficiência, estética e custo.

Quanto ao conceito de ecodesign, o Ministério do Meio Ambiente (2011), define como todo o processo que contempla os aspectos ambientais, sendo que seu objetivo principal é projetar ambientes, desenvolver produtos e executar serviços que de alguma maneira irão reduzir o uso dos recursos não renováveis ou ainda minimizar o impacto ambiental dos mesmos durante seu ciclo de vida.

Karlsson e Luttopp (2006, p. 1291), ampliam a definição no escopo da sustentabilidade. Para eles ecodesign é um conceito que inclui as prioridades da sustentabilidade humana junto às interrelações dos negócios, cujo objetivo principal na melhora dos métodos de desenvolvimento dos produtos é reduzir os impactos ambientais.

Para van Hemel e Cramer (2002), pode-se atribuir ao ecodesign o significado de uma discussão sistemática e consistente para melhorar o perfil ambiental do produto em todas as fases do ciclo de vida, incluindo reciclagem adequada e disposição.

Fundamentado nos conceitos mencionados, pode-se afirmar que o ecodesign é definido como o desenvolvimento de produtos verdes, ou seja, produtos que, além 
dos atributos inerentes ao design tradicional, há a inserção da dimensão ambiental considerando todo o seu ciclo de vida.

\subsection{Produto Verde}

A literatura traz diversos significados de "verde". Estudo realizado por Dangelico e Pontrandolfo (2010), concluiu que os conceitos são muito amplos e contemplam diferentes dimensões (ecológica, política, capacidade de resposta social empresarial, comérci o justo, conservação, tais como, sem fins lucrativos, o novo consumismo, sustentabilidade e igualdade), gerando confusão sobre o significado de verde e não fornece instruções claras para as empresas dispostas a se tornarem "verdes". O estudo apresenta algumas definições de produtos verdes. Dentre elas destacam-se:

- Peattie (1995, p. 181), define como um produto verde "quando o meio ambiente

e seu desempenho social, em produção, utilização e disposição é melhorado

significativamente em comparação com o convencional ou competitivo em ofertas de produtos". Esta definição destaca as diferentes fases do ciclo de vida durante as quais um produto pode mostrar as suas características ambientalmente amigáveis (DANGELICO \& PONTRANDOLFO, 2010).

- Reinhardt (1998, p. 46), afirma que produtos ambientais ocorrem quando: "uma empresa cria produtos que proporcionam maiores benefícios ambientais, ou que impõem menores custos ambientais do que produtos similares".

Esta definição aponta que os produtos verdes não são apenas os produtos com menor imp acto ambiental, mas também aqueles que fornecem maiores benefícios am bientais em relação aos produtos convencionais (DANGELICO \& PONTRANDOLFO, 2010).

- Ottman et al (2006, p. 24), afirmam que "embora nenhum produto consumido tenha um impacto zero sobre o meio ambiente, nos negócios, os termos "Produtos verdes" ou "Produtos ambientais" são comumente usados para descrever aqueles que se esforçam para proteger ou melhorar o ambiente natural pela conservação de energia e/ou recursos e reduzir ou eliminar o uso de agentes tóxicos, poluição e resíduos". Essa definição destaca os principais tipos de foco ambiental de desenvolvimento de produtos verdes, ou seja, energia, recursos, a poluição e o desperdício (DANGELICO \& PONTRANDOLFO, 2010).

- A Comissão das Comunidades Europeias (CCE) (2001), define produtos verdes como os produtos que "usam menos recursos, têm menores impactos e riscos ao meio ambiente e nenhuma geração de desperdício já na fase de 
concepção". Esta definição enfatiza a importância de projetar produtos como "verdes" desde a fase de conceituação (DANGELICO \& PONTRANDOLFO, 2010).

Observa-se que, conforme as definições descritas anteriormente, o produto "verde" deve causar menor impacto ambiental, utilizar menos recursos e energia e reduzir o uso de material tóxico, poluição e resíduos durante todo o ciclo de vida.

Neste sentido, as ferramentas de ecodesign se caracterizam como instrumentos de apoio a projetos de produtos verdes. Estudo realizado por Baumann; Boons e Bragd (2002), identificou mais de 150 ferramentas de ecodesign. Algumas possibilitam a avaliação dos impactos ambientais dos produtos em todas as fases do ciclo de vida, o que facilita a identificação de oportunidades de melhoria do desempenho ambiental do produto, a exemplo das ferramentas Ecodesign PILOT e a TEE, as quais serão usadas como base para a presente pesquisa.

\subsection{Ecodesign PILOT}

O Ecodesign PILOT é uma ferramenta qualitativa que permite identificar medidas concretas de ecodesign para melhoria do desempenho ambiental do produto, criada pelo Instituto de Engenharia de Design da Universidade de Viena, cuja versão original, foi desenvolvida em 2001.

A fim de melhorar as medidas de desempenho ambiental cada produto requer adoção de estratégias específicas, dependendo do seu impacto ambiental em diferentes fases do ciclo de vida. Por estas razões, o Ecodesign PILOT classifica os produtos em cinco tipos, a saber:

- Tipo A - Produto Intensivo em Matéria-prima: A quantidade de energia e materiais utilizados na extração ou fabricação das matérias-primas utilizadas no produto determinam o desempenho ambiental do produto.

- Tipo B - Produto Intensivo em Fabricação: O processo de transformação da matéria-prima causa a carga ambiental principal do produto.

- Tipo C - Produto Intensivo em Transporte: O transporte e acondicionamento são dominantes para o impacto ambiental do produto.

- Tipo D - Produto Intensivo em Uso: O consumo de energia e/ou materiais e a quantidade de resíduos gerados durante o uso determinam o desempenho ambiental do produto.

- Tipo E - Produto Intensivo em Disposição: A disposição causa os impactos ambientais principais.

Identificada a fase do ciclo de vida com mais alto impacto ambiental, o Ecodesign

PILOT propõe recomendações das estratégias de ecodesign mais adequadas para melh 
oria do produto, a partir de uma avaliação que considera: ideias de melhora, custos, viabilidade e realização.

\subsection{Teia das Estratégias do Ecodesign (TEE)}

Desenvolvida pelo PNUMA, a TEE é utilizada para avaliação preliminar do desempenho ambiental de um produto, o que permite a definição de prioridades de intervenção para que melhorias possam ser realizadas (FARGNOLI \& KIMURA, 2006). Nascimento e Venzke (2006) reforçam que por meio de uma avaliação qualitativa, um produto pode ser avaliado e desenvolver estratégias para melhorar o seu desempenho ambiental.

Para subsidiar a avaliação do produto, a ferramenta apresenta oito estratégias genéricas de ecodesign e 33 princípios, classificadas em nível de componentes do produto, nível de estrutura do produto e nível de sistema do produto, conforme descrito na figura 1.

\begin{tabular}{|c|c|c|}
\hline & Estratégicas Genéricas & Princípios \\
\hline - & $\begin{array}{l}\text { @. Desenvolvimento de } \\
\text { novo conceito }\end{array}$ & $\begin{array}{l}\text { @.1 Desmaterialização } \\
\text { @.2 Uso compartilhado do produto } \\
@ .3 \text { Integração de funções } \\
\text { @.4 Otimização funcional do produto ou } \\
\text { componente }\end{array}$ \\
\hline $\begin{array}{l}\text { Nível de } \\
\text { componentes do } \\
\text { produto }\end{array}$ & $\begin{array}{l}\text { 1. Seleção de materiais de } \\
\text { baixo impacto } \\
\text { 2. Redução do uso de } \\
\text { materiais }\end{array}$ & $\begin{array}{l}\text { 1.1 Materiais não agressivos } \\
\text { 1.2 Materiais renováveis } \\
\text { 1.3 Materiais reciclados } \\
\text { 1.4 Materiais de baixo conteúdo energético } \\
\text { 1.5 Materiais recicláveis } \\
\text { 2.1 Redução de peso } \\
\text { 2.2 Redução de volume } \\
\text { 2.3 Racionalização de transportes }\end{array}$ \\
\hline $\begin{array}{l}\text { Nível de } \\
\text { estrutura do } \\
\text { produto }\end{array}$ & $\begin{array}{l}\text { 4. Sistema de distribuição } \\
\text { eficiente } \\
\text { 5. Redução do impacto } \\
\text { ambiental no nível do } \\
\text { usuário }\end{array}$ & $\begin{array}{l}\text { 3.1 Técnicas de produção alternativas } \\
\text { 3.2 Redução de etapas de processo de produção } \\
\text { 3.3 Redução do consumo e uso racional de energia } \\
\text { 3.4 Uso de energias mais limpas } \\
\text { 3.5 Redução da geração de refugos/resíduos } \\
\text { 3.6 Redução e uso racional de insumos de } \\
\text { produção. } \\
\text { 4.1 Redução e uso racional de embalagens } \\
\text { 4.2 Uso de embalagens mais limpas } \\
\text { 4.3 Uso de sistemas de transporte eficientes } \\
\text { 4.4 Logística eficiente } \\
\text { 5.1 Baixo consumo energético } \\
\text { 5.2 Uso de fontes de energias mais limpas } \\
\text { 5.3 Uso racional e redução de insumos durante a } \\
\text { aplicação } \\
\text { 5.4 Uso de insumos limpos }\end{array}$ \\
\hline
\end{tabular}


5.5 Prevenção de desperdícios pelo design.

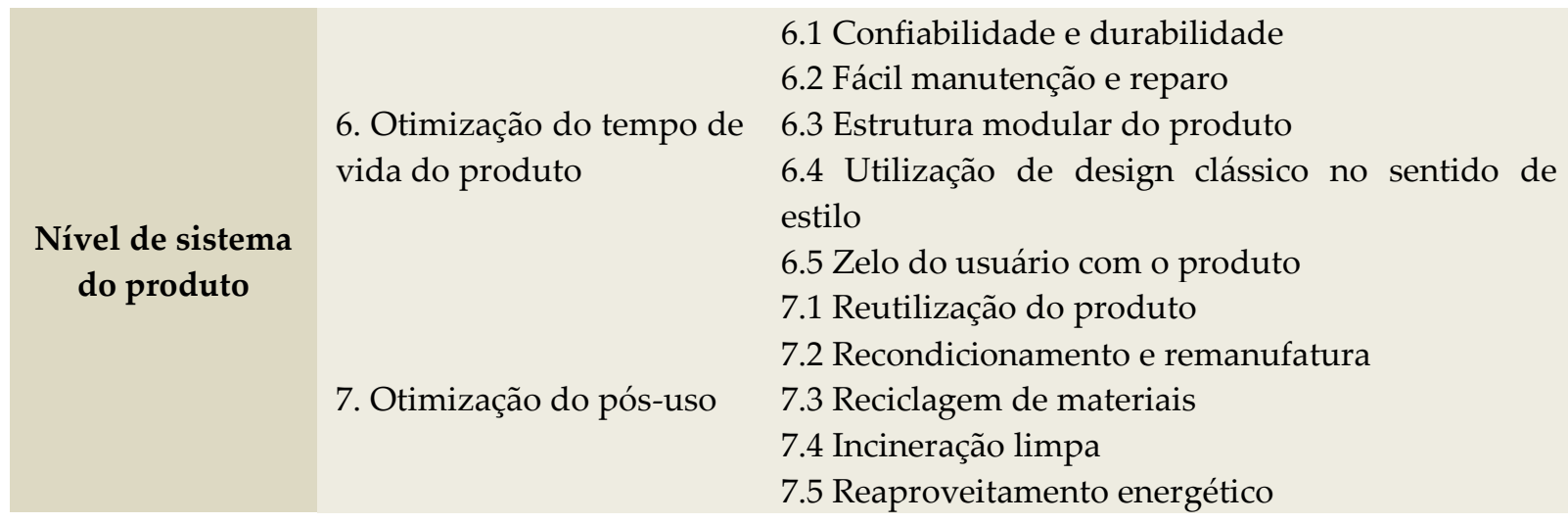

Figura 1 - Estratégias do Ecodesign

Fonte: Adaptado de van Hemel e Cramer (2002)

Essas estratégias abrangem todo o ciclo de vida de um produto, guiando designers para a melhoria ambiental dos seus produtos. Embora este método se concentre em produtos manufaturados, muitas das estratégias podem ser igualmente aplicáveis aos produtos artesanais ou serviços (FARGNOLI \& SAKAO, 2008).

Uma vez utilizada os resultados são representados num gráfico tipo teia e representam uma variação de 20 pontos percentuais, que vai de $0 \%$ (centro da figura) até $100 \%$ (último círculo). O centro da teia representa um desempenho ambiental inadequado e o círculo mais externo, um ótimo desempenho. A meta da ferramenta é prover as melhores opções para melhoria ambiental de um produto (FARGNOLI \& SAKAO, 2008).

\section{ASPECTOS METODOLÓGICOS}

Esta pesquisa, em relação aos objetivos propostos, classifica-se como exploratória e descritiva, uma vez que o estudo analisa as estratégias de ecodesign de um produto concebido como verde, utilizando as ferramentas Ecodesign PILOT e TEE. Para Hair Jr. et al (2005), a pesquisa exploratória é realizada em área na qual há pouco conhecimento. A descritiva busca descrever as características de determinada população ou fenômeno, bem como estabelecer correlações entre variáveis e definir sua natureza, sem o compromisso de explicá-los (VERGARA, 2000).

Quanto ao método se optou pelo estudo de caso. Tal método diz respeito ao estudo de uma ou de poucas unidades, de maneira a permitir entendimento profundo e detalhado do que está sendo analisado (VERGARA, 2000; GIL, 2002).

O produto escolhido foi o bloco cerâmico econômico, por se tratar de um produto concebido como "verde", o qual apresenta a redução de custos da obra e a sustentabilidade como atrativos para os clientes. Fabricado em Campina Grande PB, pela Protótipos Engenharia, o produto apresenta as mesmas dimensões dos blocos já fabricados, todavia pesa menos que o bloco convencional. Conforme o fabricante, devido à penetração do calor pelos furos nas laterais do bloco, o tempo de 
queima e secagem é reduzido, o que leva a um consumo menor de lenha. O produto elimina a etapa do chapisco e, consequentemente, diminui a quantidade de cimento, areia e mão de obra, tornando mais rápida a conclusão da obra.

A coleta de dados foi obtida junto ao idealizador do produto e gestor da empresa através de entrevista semiestuturada e dois questionários. Para conhecer a intensividade dos aspectos ambientais do produto analisado (matéria-prima, fabricação, transporte, uso ou disposição) adotou-se, na íntegra, o questionário do Ecodesign PILOT.

O segundo questionário foi elaborado a partir da TEE e do Ecodesign PILOT, no qual foram abordadas as oito estratégias de ecodesign, desmembradas em 34 dimensões, e, para cada dimensão foram elaboradas afirmativas, totalizando 71 afirmativas, das quais a maioria era fechada, e, em alguns casos, abertas para possíveis informações complementares.

Para cada alternativa, tomando como base na ferramenta Ecodesign PILOT, as respostas do segundo questionário foram assinaladas considerando dois aspectos: percepção sobre a relevância e efetiva aplicação, considerando que as afirmativas podem ter diferentes níveis de relevância e de aplicação, que a percepção de algo como relevante nem sempre resulta em sua aplicação e que a aplicação também é influenciada pelo nível de relevância percebido. A percepção sobre a relevância apresentava três níveis: nenhuma relevância (0); pouca relevância (5) e muita relevância (10), e a efetiva aplicação quatro níveis: sempre aplico (1); quase sempre aplico (2); às vezes aplico (3) e não aplico (4). Com base nessas informações se pode verificar a percepção que se tem sobre a relevância dos aspectos de ecodesign e a efetiva aplicação de tais aspectos, para cada uma das oito estratégias de ecodesign.

Como as oito estratégias se apresentam de modos diferentes, fez-se necessário a identificação de quais estratégias devem ser prioritárias para que possam ser trabalhadas. A prioridade foi encontrada a partir do produto entre a relevância $(0,5$, 10) e a aplicação $(1,2,3,4)$, podendo chegar aos seguintes resultados: $0,5,10,15,20$, 30 e 40. Quanto mais alto for o resultado maior será a prioridade, ou seja, maior relevância e menor aplicação.

Considerando os possíveis resultados encontrados $(0,5,10,15,20,30$ e 40) para definir as prioridades de cada estratégia, e, como forma de dar mais consistência a análise, a prioridade foi classificada em três níveis: baixa (0-13), média (14-26) e alta (27-40). Desta forma, cada estratégia teve suas respectivas dimensões analisadas e identificadas as prioridades de cada afirmativa. A prioridade de cada dimensão aplicável ao produto foi calculada por meio da média aritmética de suas respectivas afirmativas aplicáveis ao produto. A prioridade de cada estratégia foi calculada por meio da média aritmética de suas respectivas dimensões.

No que se refere aos dados secundários, foram usados manuais, documentação e informações técnicas sobre o produto. Após a obtenção dos dados primários e secundários, procedeu-se a sua organização, considerando as 
características e os objetivos do estudo, os dados foram tratados qualitativa e quantitativamente.

\section{ANÁLISE E DISCUSSÃo DOS RESULTADOS}

\subsection{Intensividade dos aspectos ambientais, segundo o Ecodesign PILOT}

Para análise do bloco cerâmico econômico utilizando o questionário do Ecodesign PILOT, foi considerado uso de 365 dias por ano e uma vida útil de 50 anos. Os materiais utilizados foram informados, conforme o Quadro 1.

\begin{tabular}{|l|c|c|c|c|}
\hline \multicolumn{1}{|c|}{ Partes do produto } & Kg & Material & Classe & Descarte \\
\hline Bloco Cerâmico & 0,05 & Água & I & Aterro \\
\hline Bloco Cerâmico & 2,8 & Argila & I & Aterro \\
\hline
\end{tabular}

Quadro 1 - Informações sobre o "Bloco Cerâmico Econômico"

Fonte: Dados da pesquisa (2012)

No que se refere à manufatura do produto, considerou-se que não há desperdício durante o processo produtivo porque as cinzas $(0,003 \mathrm{~kg} /$ produto) da lenha utilizada na etapa de queima do produto, ricas em nutrientes, sobretudo em potássio, são reutilizadas como corretivo da acidez do solo ou adubo. O que acarretou a não inserção desse dado foi o fato do Programa disponibilizar apenas as seguintes alternativas relacionadas aos resíduos gerados na fase de produção: separação completa de material, reciclagem parcial de materiais e não classificação de materiais. Assim, escolheu-se a alternativa reciclagem parcial de materiais por ser a que mais se assemelha à destinação dada às cinzas.

A empresa não faz uso de materiais auxiliares e de processo ambientalmente perigosos. A produção é de mais de 100.000 unidades/ano, e o consumo de energia para produção de cada unidade é de 10,63 MJ. No produto não há peças externas.

Quanto à distribuição, esta é feita através de caminhões por um percurso de em média $50 \mathrm{~km}$ (distância entre a Cerâmica e Campina Grande-PB). O material de embalagem (madeira e corda para amarração dos blocos) é retornável.

No que concerne ao uso do produto, dentre as alternativas do questionário foi informado que é impossível o produto apresentar um risco potencial para o meio ambiente se for utilizado de forma inadequada ou em caso de mau funcionamento.

No fim de vida, o produto é destinado a aterro.

Com base nas informações acima, o Ecodesign PILOT classificou o bloco cerâmico econômico como tipo " $\mathrm{B}$ ", ou seja, a fase de "fabricação" é a mais significante no que concerne aos aspectos ambientais do produto. Assim, foram recomendadas as seguintes estratégias:

Estratégia de alta prioridade:

a) reduzir o consumo de energia no processo de produção. 


\section{Estratégias para serem realizadas mais tarde:}
a) otimizar tipo e quantidade de materiais de processo;
b) evitar o desperdício no processo de produção;
c) compras ecológicas de componentes externos;
d) otimizar o uso do produto;
e) otimizar a funcionalidade do produto;
f) aumentar a durabilidade do produto;
g) melhorar a manutenção;
h) melhorar a reparabilidade;
i) melhorar a desmontagem e
j) reutilização de componentes de produtos.

Quanto à estratégia de alta prioridade, que trata da redução do consumo de energia no processo de produção, o Ecodesign PILOT sugere que: a empresa utilize tecnologias de produção energicamente eficientes; reduza o consumo de energia por meio de um design ótimo do processo; utilize preferivelmente recursos de energia renováveis; utilize preferivelmente recursos energéticos regionais e minimize o consumo global de energia no local de produção.

Para a empresa, as afirmativas acima têm muita relevância e são sempre aplicadas, resultando-se em prioridade (10). De fato, faz-se uso de tecnologias de produção energeticamente eficientes quando da inserção no processo produtivo da máquina para furar os blocos, que resulta em redução do consumo de energia; faz-se uso de fonte de energia renovável (lenha) e utiliza-se de recursos energéticos regionais, o que a leva à redução das distâncias de transporte e, consequentemente, da redução do consumo de energia fóssil e da poluição atmosférica.

\subsubsection{Sugestões de melhoria ambiental para o produto a partir do Ecodesign PILOT}

Além das medidas já adotadas pela empresa visando o desempenho ambiental do produto, seria interessante a recomendação como estratégia de alta prioridade para redução do consumo de energia no processo de produção, a substituição do forno, tipo Hoffmann, por outro tipo que consuma menos energia. Entretanto, para fazer esta recomendação com base nos critérios do Programa faz-se necesário um estudo mais amplo, o que não é objeto deste trabalho.

No que tange às estratégias para serem realizadas mais tarde, constatou-se que: - Estratégias a e b: o processo de produção não gera desperdício de materiais;

- Estratégias c, i e j: o produto apresenta-se como peça única;

- Estratégia d e e: o produto reduz o prazo de entrega da obra, pois elimina a etapa do chapisco;

- Estratégias f: a vida útil estimada do produto é longa (50 anos);

- Estratégia g e h:o produto não necessita de manutenção e reparabilidade. 
Assim, conforme exposto, observou-se que todas as Estratégias recomendadas pelo Programa para serem realizadas mais tarde já têm efetiva aplicação.

\subsection{Estratégias de ecodesign e suas respectivas prioridades}

Na Estratégia 0, que trata do desenvolvimento de novo conceito (Gráfico 1), considerando-se os aspectos ambientais que devem ser incorporados na fase inicial do ciclo de vida do produto, as dimensões "desmaterialização" e "uso compartilhado do produto" não se aplicam ao produto em análise.

Com relação às dimensões "integração de funções" e "otimização funcional do produto ou componente", ambas apresentam baixa prioridade (10), pois as afirmativas aplicáveis ao produto têm muita relevância e sempre são aplicadas. Para a empresa, o produto desperta sentimentos positivos ao usuário, pois, considerandose que a etapa de chapisco é eliminada, haverá redução de custos e de tempo para conclusão da obra.

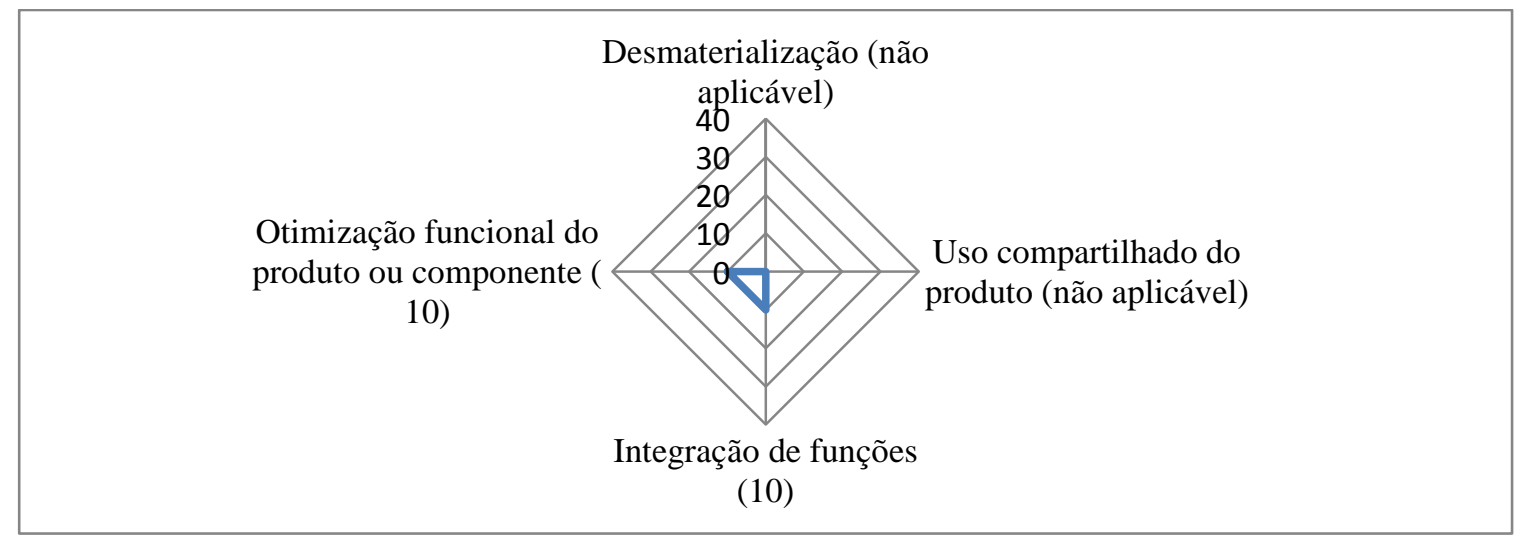

Gráfico 1 - Estratégia 0: Desenvolvimento de novo conceito Fonte: Dados da pesquisa (2012)

A baixa prioridade (10) desta estratégia é justificada pelo fato do bloco cerâmico econômico reduzir custos e agilizar a conclusão da obra, conforme já explicitado anteriormente.

A Estratégia 1, que aborda a seleção de materiais de baixo impacto ambiental apresenta-se como baixa prioridade (Gráfico 2). A empresa percebe a "utilização de materiais não agressivos" como algo muito relevante, por isso sempre "evita o uso de materiais tóxicos no produto" e o "uso de matérias-primas com problemas já conhecidos". Assim, esta dimensão totaliza prioridade (10).

Quanto à dimensão "materiais reciclados", a empresa percebe como prioridade (0), pois entende que não é necessária a reciclagem da água, uma vez que não usa água potável, e, quanto à argila, não existe a possibilidade de reciclá-la.

No que tange às dimensões "materiais renováveis", "materiais de baixo conteúdo energético" e "materiais recicláveis", todas apresentam baixa prioridade 
(5). Porém, apesar de apresentarem pouca relevância, dado ao tipo de material utilizado, sempre são aplicadas.

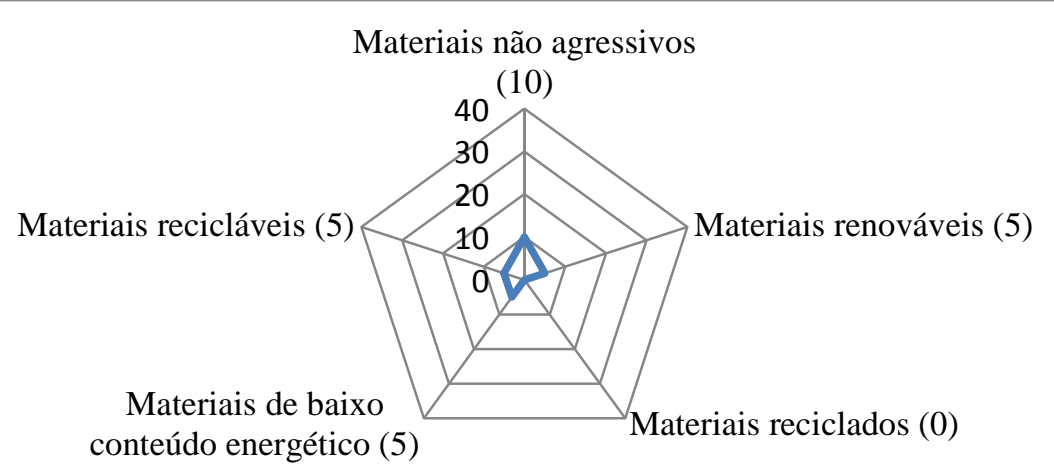

Gráfico 2 - Estratégia 1: Seleção de materiais de baixo impacto

Fonte: Dados da pesquisa (2012)

A baixa prioridade (5) desta Estratégia é justificada pelo fato da empresa não utilizar no produto materiais tóxicos ou com problemas já conhecidos, escassos ou em risco de extinção, como a água potável; bem como utilizar materiais que demandam pouca energia em sua transformação, pois a Cerâmica está estabelecida nas proximidades das jazidas de argila.

Embora utilize materiais que podem ser reciclados, tornando-os materiais para serem reutilizados na fabricação de novos produtos, a empresa não os reutiliza por não ter linha de produção que recicle os resíduos da construção civil.

Tratando-se da Estratégia 2, que aborda a redução de uso de materiais (Gráfico 3), para a empresa, as dimensões: "redução de peso" e "redução de volume" não são aplicáveis ao bloco cerâmico econômico, pois os materiais utilizados (água e argila) são os mesmos utilizados na fabricação de blocos cerâmicos tradicionais.

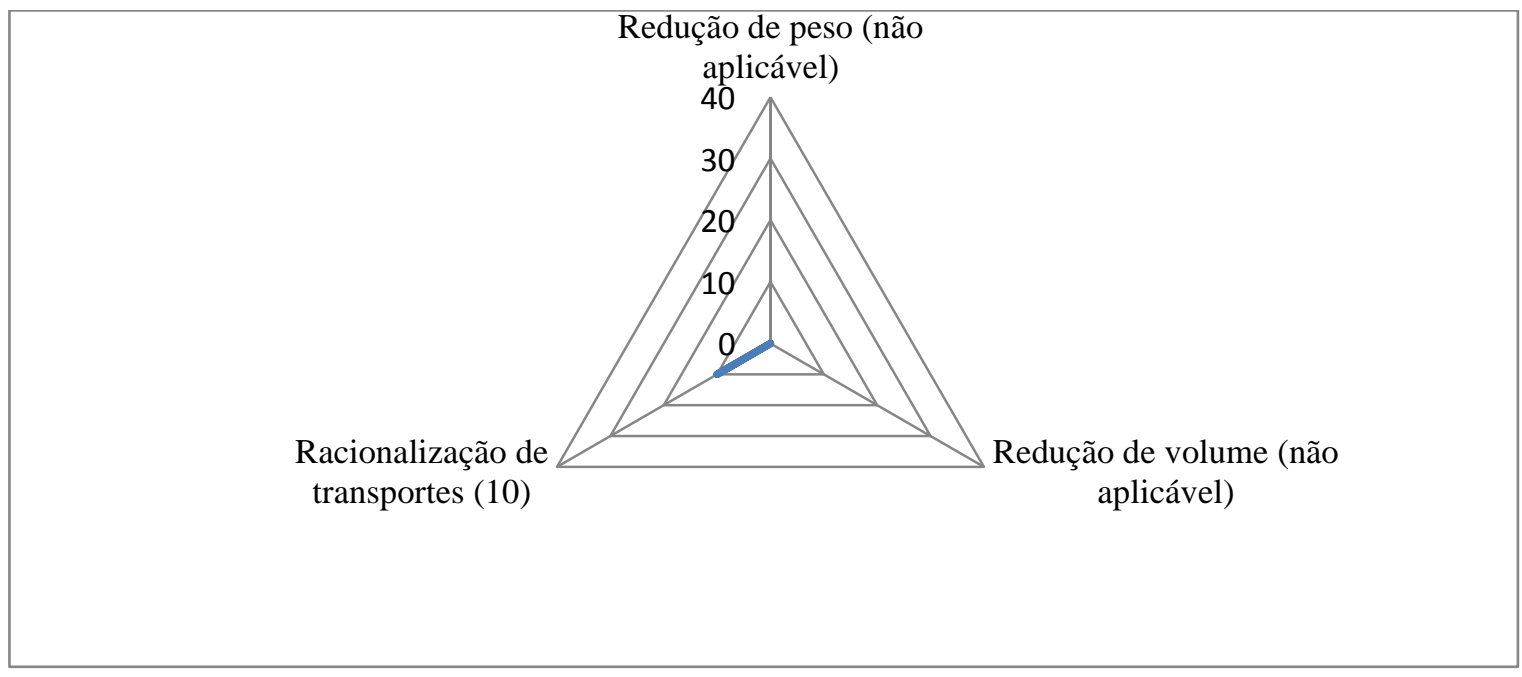

Gráfico 3 - Estratégia 2: Redução de uso de materiais 
Fonte: Dados da pesquisa (2012)

No que concerne à dimensão "racionalização de transportes", apenas a afirmativa "preferência por matérias-primas, produzidas localmente, para minimização das distâncias de transporte" tem aplicabilidade. Esta afirmativa, por ter muita relevância é sempre aplicada. Assim, tanto esta afirmativa, quanto as respectivas dimensão e estratégia, resultam em prioridade (10), que caracteriza-se como de baixa prioridade.

Para minimização das despesas de transporte, a Cerâmica está instalada nas proximidades das jazidas de argila e de reservatórios de água.

Quanto à Estratégia 3, que se refere a otimização das técnicas de produção (Gráfico 4), a empresa percebe muita relevância e sempre têm aplicação as seguintes dimensões: "técnicas de produção alternativa", " redução de etapas do processo de produção", "redução do consumo e uso racional de energia", " uso de energia mais limpa" e " redução e uso racional de insumos de produção". Assim, com prioridade igual a (10), estas dimensões caracterizam-se como baixa prioridade.

Apesar da dimensão "redução da geração de refugos/resíduos" apresentar $\underline{\text { média }}$ prioridade (15), a Estratégia caracteriza-se como de baixa prioridade $(\mathbf{1 0 , 8 3})$.

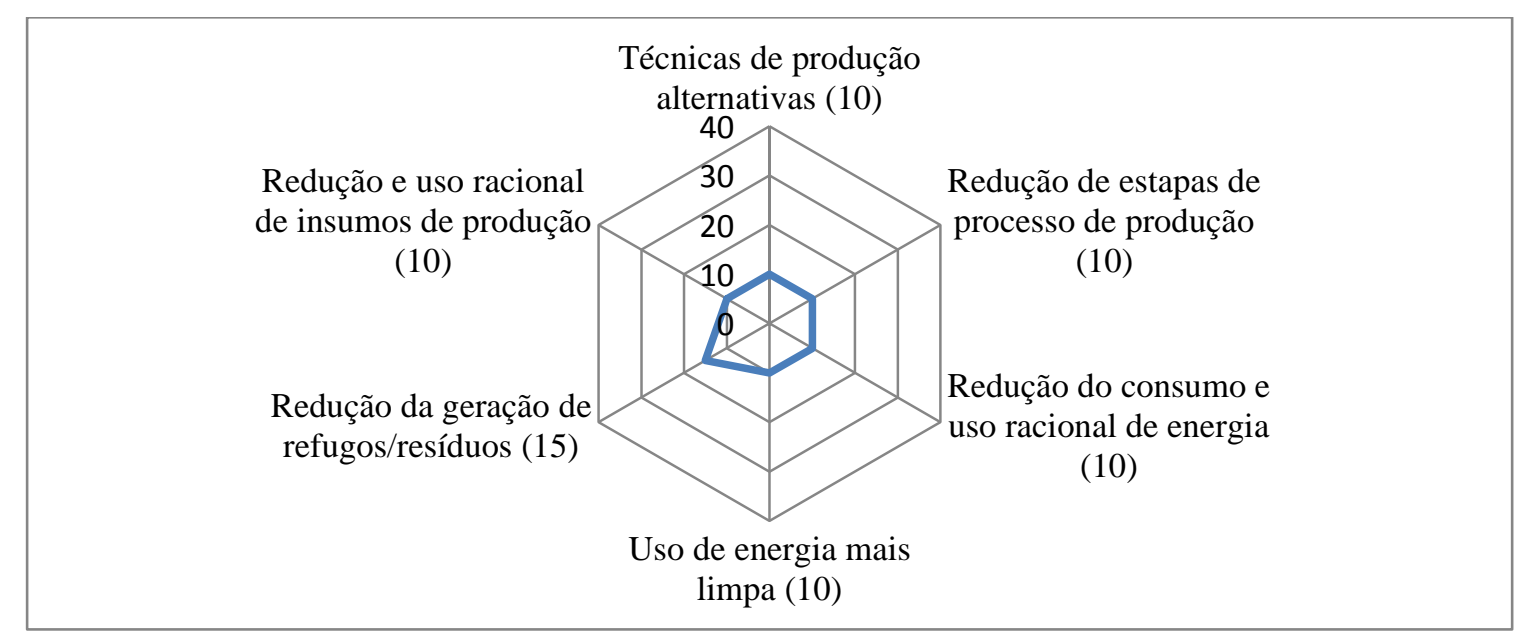

Gráfico 4 - Estratégia 3: Otimização das técnicas de produção

Fonte: Dados da pesquisa (2012)

A baixa prioridade desta Estratégia é justificada principalmente pela introdução da furadeira, que reduz o consumo de insumos (água, argila e lenha) e diminui o tempo de queima do produto. Outro fator importante é a secagem a frio do produto que é $30 \%$ mais rápida que dos blocos tradicionais; enquanto os tradicionais necessitam de 2 a 3 dias, o bloco cerâmico econômico necessita de 1 a 2 dias para secagem.

O processo de produção praticamente não gera resíduo, apenas 0,003 kg de cinza/bloco. As cinzas geradas pela queima da lenha não podem ser reutilizadas dentro do processo produtivo, todavia, são reutilizadas como corretivos de solo. 
Vale ressaltar que o consumo menor de lenha implica diretamente em redução de elementos na atmosfera (monóxido de carbono, gás carbônico, cinza, fuligem, etc.).

Quanto à Estratégia 4, que aborda aspectos inerentes ao sistema de distribuição eficiente (Gráfico 5), as dimensões: "redução e uso racional de embalagens" e "uso de embalagens mais limpas" não se aplicam ao bloco cerâmico, haja vista que o produto não necessitar de embalagem, e, quando do transporte, como exposto anteriormente, as embalagens (madeira e corda para amarração) retornarem à empresa.

No que tange às dimensões, "uso de sistemas de transportes eficientes" e "logística eficiente", ambas apresentam baixa prioridade (11,7) e (10), respectivamente.

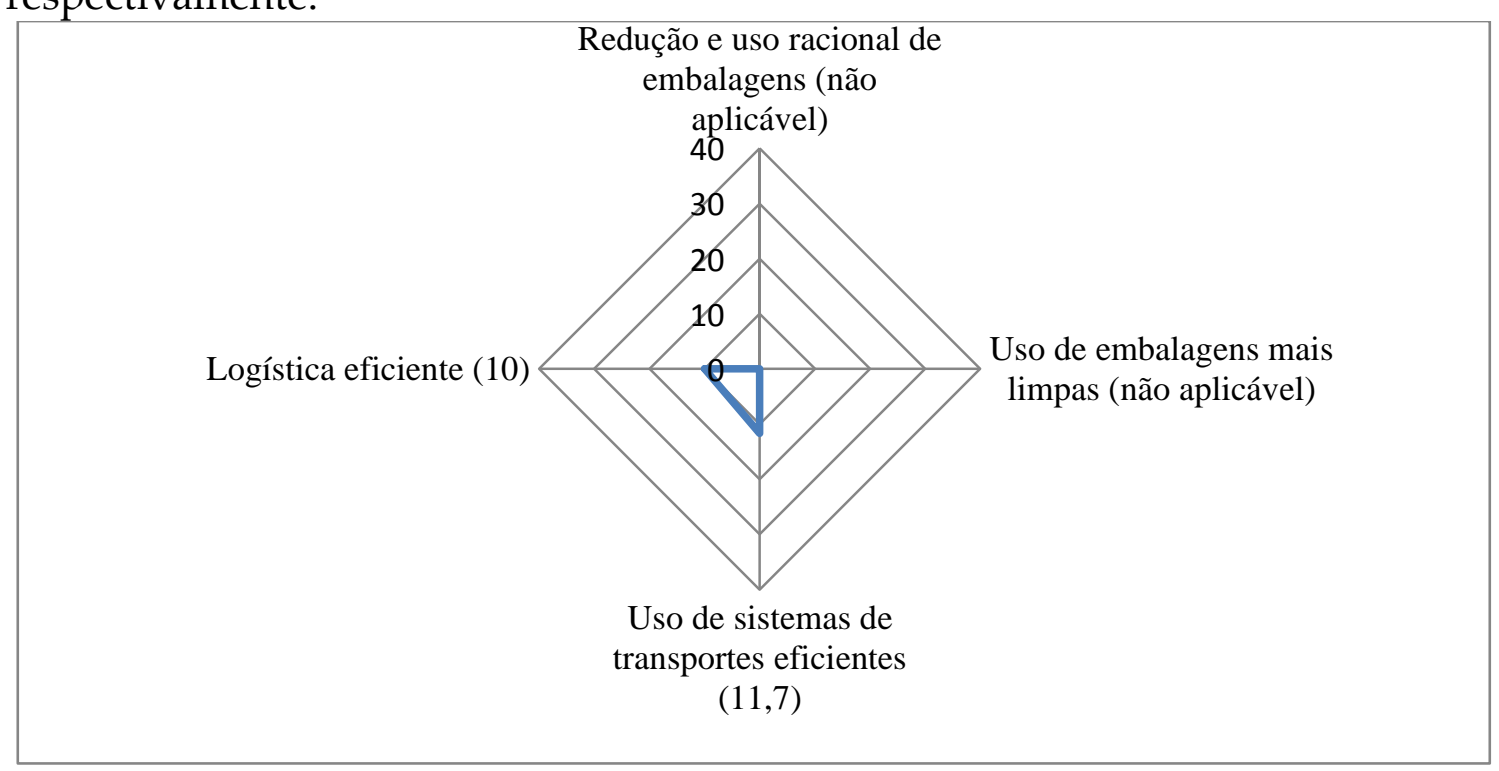

Gráfico 5 - Estratégia 4:Sistema de distribuição eficiente Fonte: Dados da pesquisa (2012)

Considerando-se as duas dimensões aplicáveis ao bloco cerâmico econômico, esta Estratégia tem baixa prioridade $(\mathbf{1 0 , 8 5 )}$. Dada à localização da empresa e o atual mercado consumidor (Campina Grande-PB), o meio de transporte utilizável e mais viável é o rodoviário (caminhão) em que faz-se utilização da capacidade total do meio de transporte e definição de critérios para planejamento das rotas em conformidade com a ordem de datas dos pedidos.

No que tange à Estratégia 5, que trata da redução do impacto ambiental no nível de usuário (Gráfico 6), para o bloco cerâmico as dimensões "baixo consumo energético" e "prevenção de desperdícios pelo design", bem como as afirmativas relacionadas à limpeza e manutenção do produto não são aplicáveis.

Para a empresa, no nível do usuário, têm muita relevância e são sempre aplicadas a 
"redução de insumos" e a "utilização de materiais não tóxicos ou perigosos durante a aplicação" do bloco cerâmico econômico, o que resulta em prioridade (10).

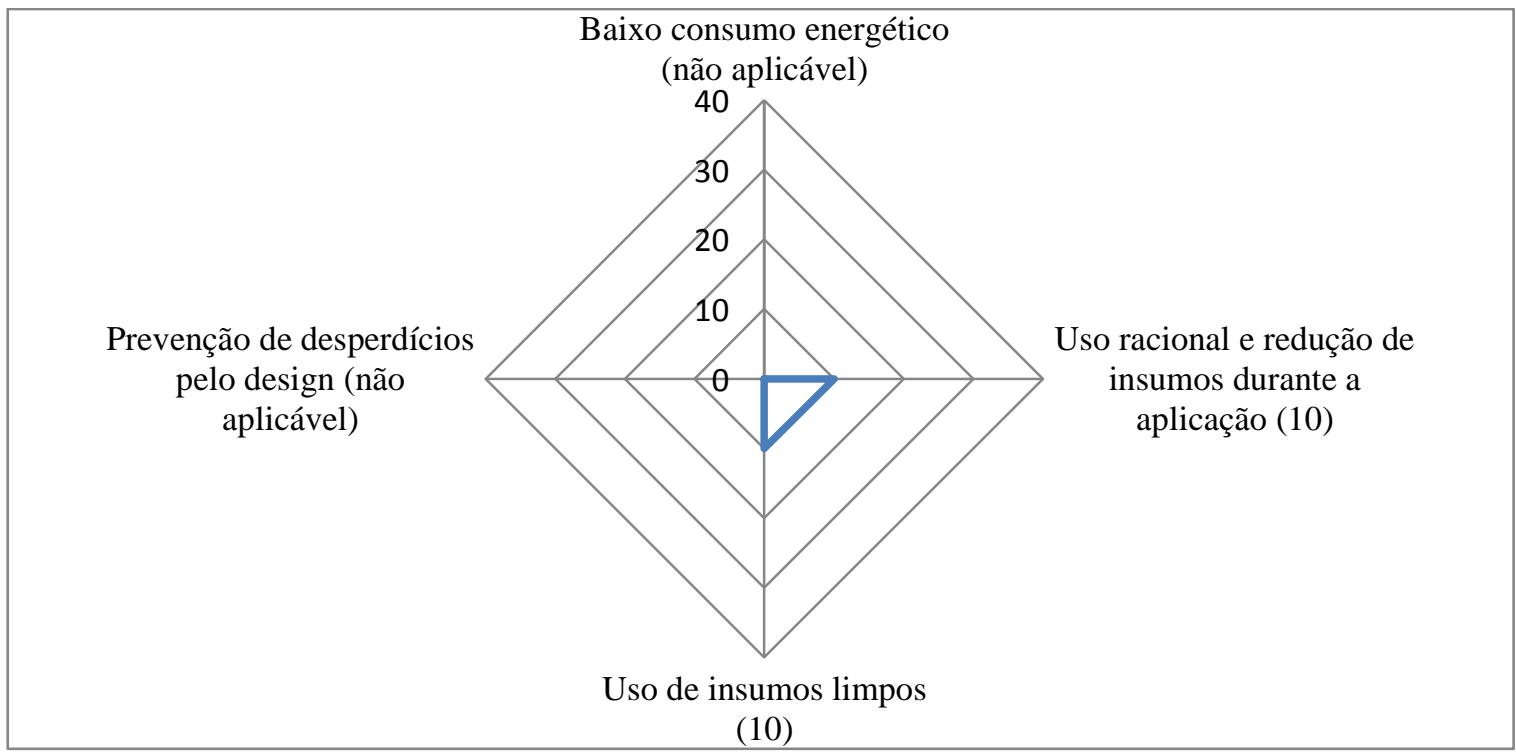

Gráfico 6 - Estratégia 5: Redução do impacto ambiental no nível do usuário Fonte: Dados da pesquisa (2012)

A baixa prioridade desta Estratégia (10) justifica-se pelo fato do usuário, quando da aplicação do bloco cerâmico econômico, utilizar menos argamassa (cimento, água e areia) devido aos furos nas laterais do bloco, que levam à eliminação da fase de chapisco.

Em relação à Estratégia 6, que se refere a otimização do tempo de vida do produto (Gráfico 7), as dimensões: "fácil manutenção e reparo", "estrutura modular do produto", "utilização de design clássico no sentido de estilo" e "zelo do usuário com o produto" não são aplicáveis, haja vista o produto não necessitar de cuidados, manutenção e reparo, ser peça única e seguir padrões já estabelecidos.

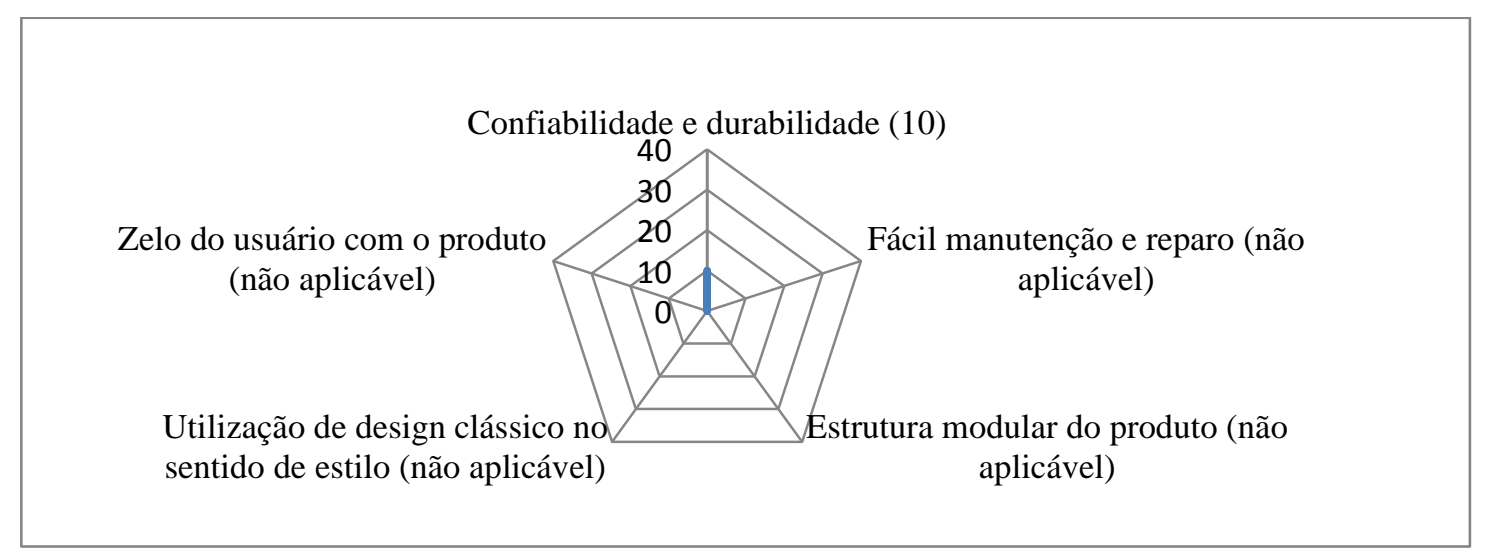

Gráfico 7 - Estratégia 6: Otimização do tempo de vida do produto Fonte: Dados da pesquisa (2012) 
Neste caso, a única dimensão aplicada ao produto faz referência à sua "confiabilidade e durabilidade", de modo que as afirmativas: "o produto é projetado para durar e pode lidar com os encargos de uso intensivo" e "os materiais utilizados conservam características como cor e forma" têm muita relevância e são sempre aplicadas, de forma que a prioridade de cada uma destas afirmativas, desta dimensão e desta Estratégia é (10), o que caracteriza-se baixa prioridade.

Finalizando-se com a Estratégia 7, que aborda a otimização do pós-uso (Gráfico 8), evidencia-se que, conforme as afirmativas apresentadas, as dimensões: "reutilização do produto" e "recondicionamento e remanufatura" não são aplicáveis ao bloco cerâmico.

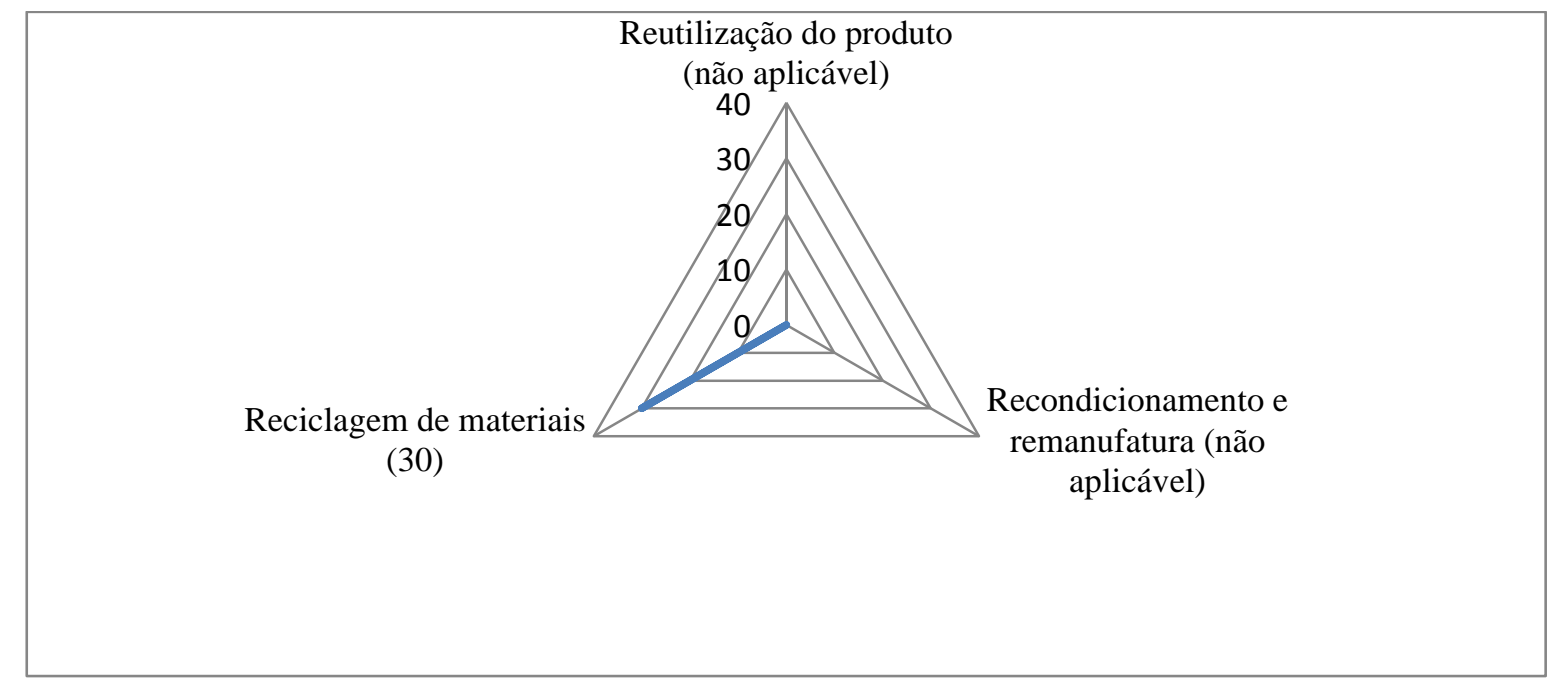

Gráfico 8 - Estratégia 7: Otimização do pós-uso

Fonte: Dados da pesquisa (2012)

Em se tratando da dimensão "reciclagem de materiais" apenas a afirmativa “os materiais utilizados permitem a reciclagem" é aplicável ao produto em análise. Para a empresa esta afirmativa tem muita relevância. Entretanto, devido à prática de não se reciclar resíduos da construção civil, que via de regra são destinados a aterros ou lixões, apenas às vezes é aplicada, o que resulta em prioridade (30).

Desta forma, considerando-se que é aplicável ao produto apenas uma afirmativa e uma dimensão, esta estratégia também tem prioridade (30), o que se caracteriza alta prioridade. Ressalta-se que, para a empresa, torna-se difícil aplicar estratégias que reduzam a prioridade de otimização do pós-uso do bloco cerâmico econômico, em virtude da longa vida útil do produto e, consequentemente, da impossibilidade de identificação do gerador responsável pela destinação do resíduo.

\subsection{Relação entre intensividade dos aspectos ambientais (Ecodesign PILOT) e as estratégias de ecodesign (TEE)}

Conforme apresentado na Figura 2, o bloco cerâmico econômico apresenta-se, conforme resultado do Ecodesign PILOT intensivo em fabricação, ou seja, o consumo 
de energia e materiais na fase de fabricação determina o desempenho ambiental do produto. Por outro lado, a Estratégia da TEE, que trata da "Otimização das técnicas de produção", justifica-se como de baixa prioridade devido à introdução da furadeira na fase de produção, a qual leva, em razão dos furos nas laterais do bloco, à redução do consumo de energia, que é de fonte renovável (madeira), além da redução do tempo de queima, da redução do tempo de secagem a frio e da redução e uso racional de insumos (água, argila e lenha).

Ainda ao que se refere à TEE, a "Otimização do pós-uso" apresenta-se como alta prioridade devido, como já dito anteriormente, o bloco cerâmico, como resíduo da construção civil, ainda não ser habitualmente reciclado.

Observa-se que as demais características do Ecodesign PILOT convergem para as respectivas Estratégias da TEE, as quais apresentam-se como de baixa prioridade.

\section{Características do Ecodesign PILOT}

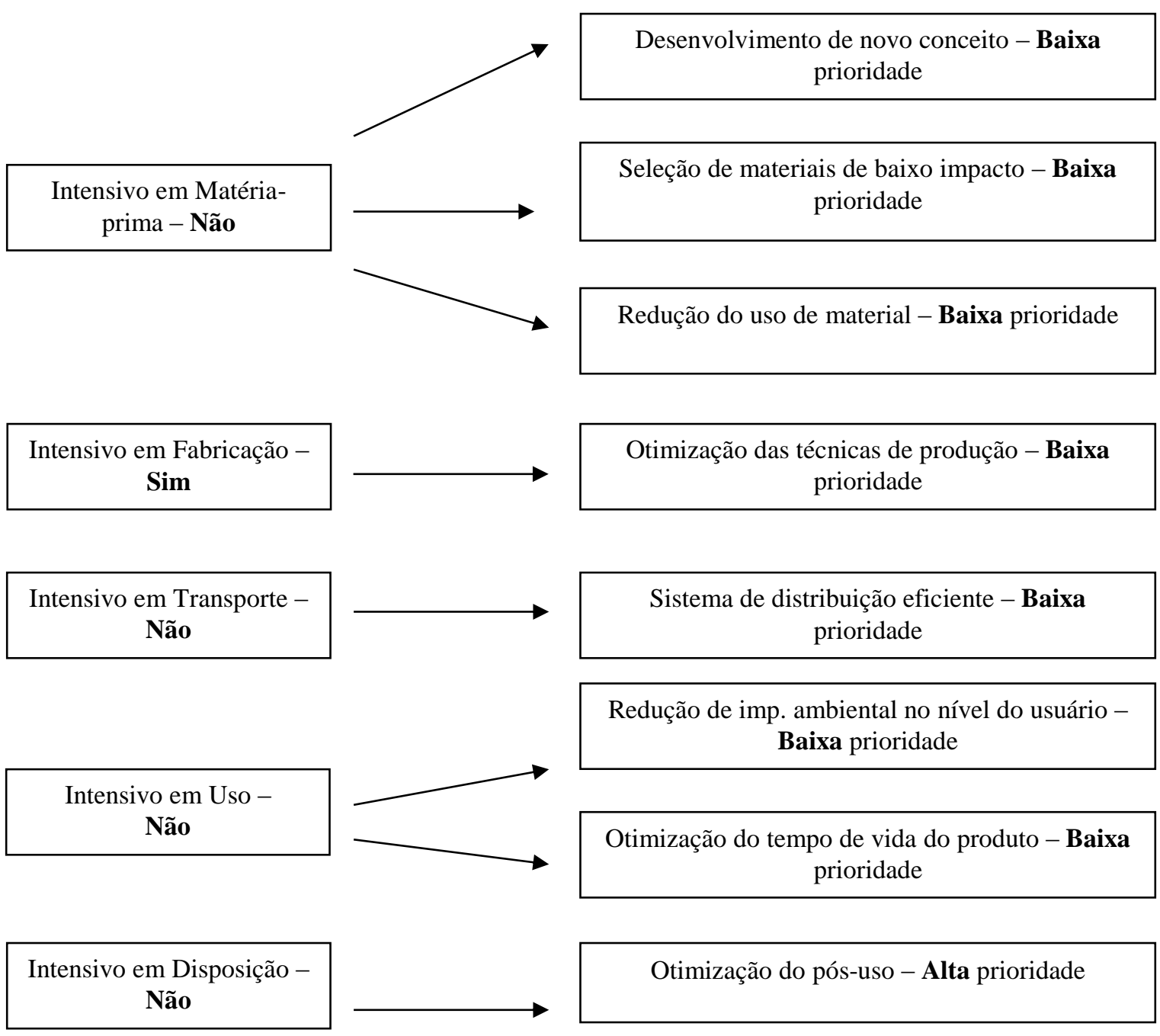

Figura 2 - Relação de complementaridade entre o Ecodesign PILOT e a TEE. 
Com efeito, o fato dos resultados das ferramentas utilizadas apresentarem resultados, na sua maioria, convergentes, reforça-se a importância e necessidade do uso combinado do Ecodesign PILOT e da TEE para análise mais ampla do desempenho ambiental do produto.

Após a realização de todas as análises, pode-se elencar, entre outros, os seguintes aspectos ambientais do bloco cerâmico econômico: os materiais utilizados não causam impactos ambientais; durante o processo produtivo não há praticamente geração de resíduos; em ralação aos blocos tradicionais, o consumo de energia na fase de produção é reduzido; a energia utilizada é de fonte renovável; o produto tem uma vida útil longa; durante a aplicação reduz etapa da obra (chapisco) e, consequentemente, o uso de materiais (argamassa); pode ser reciclado; o produto em si, não necessita de embalagem e devido aos furos nas laterais, pesa $1 \%$ a menos comparado aos blocos tradicionais, o que reduz o uso de combustível fóssil e emissão de dióxido de carbono durante o transporte.

Em suma, diante do exposto, pode-se afirmar que o bloco cerâmico econômico, concebido como produto verde, à luz do Ecodesign PILOT e da TEE, é de fato um produto verde, haja vista que os aspectos ambientais do produto se apresentaram positivamente.

\section{CONSIDERAÇÕES FINAIS}

O objetivo deste trabalho foi avaliar se o bloco cerâmico econômico, concebido como produto verde, de fato é verde. Os aspectos ambientais do produto foram analisados a partir do uso de duas ferramentas de ecodesign: o Ecodesign PILOT e a TEE, as quais contemplam todas as etapas do ciclo de vida do produto, cujos resultados mostraram que de fato o produto pode ser considerado como verde.

Cabendo destacar a importância da ampliação das discussões em torno dos produtos verdes, considerando por um lado, a tendência de crescimento desse tipo de produto e a possibilidade de uma efetiva contribuição à construção de um desenvolvimento econômico mais sustentável, e, por outro lado, a necessidade de um maior esclarecimento para as organizações e consumidores sobre o que de fato deve ser considerado como produto verde, evitando o uso de apelo ambiental com propósitos ludibriantes.

É importante ressaltar que os objetivos deste estudo foram alcançados, apesar de algumas alternativas oferecidas pelo Programa Assistente do Ecodesign PILOT não se aplicarem ao produto analisado, o que levou a pesquisadora a selecionar a alternativa que mais se adéqua, já que em algumas questões, necessariamente tem que se optar por uma das alternativas disponíveis.

Assim sendo, frisa-se que a pesquisa trás importantes contribuições do ponto de vista prático e teórico. Em termos práticos permitiu avaliar os atributos verdes do 
produto em estudo, evidenciando empiricamente, que a criação de produtos verdes pelas organizações poderá se apresentar como prática real e não apenas engodos mercadológicos. Do ponto de vista teórico, contribui para a discussão sobre produtos verdes na perspectiva das estratégias de ecodesign, área de conhecimento ainda em construção, sobretudo, focando na discussão da necessidade de uma avaliação mais ampla do desempenho ambiental dos produtos verdes, principalmente, ao considerar todas as etapas do ciclo de vida do produto, e não apenas um aspecto do produto.

Quanto a futuros trabalhos, em face da importância do uso conjunto do Ecodesign PILOT e a TEE, sugere-se a avaliação de outros produtos concebidos como verdes ou produtos, que embora não tenham sido concebidos como tal, possam melhorar seu desempenho ambiental, utilizando tais ferramentas.

\section{REFERÊNCIAS}

BARBIERI, J. C. Gestão ambiental empresarial: conceitos, modelos e instrumentos, 2. ed. São Paulo: Saraiva, 2007.

BAUMANN, H.; BOONS, F.; BRAGD, A. Mapping the green product development field: engineering, policy and business perspectives. Journal of Cleaner Production, v. 10, 2002, pp. 409-425.

BREZET, H.; van HEMEL, C. Ecodesign, A promising approach to sustainable production and consumption. Edited by UNEP. Paris, 1997.

BYGGETH, S.; HOCHSCHORNER, E. Handling trade-offs in ecodesign tools for sustainable product development and procurement. Journal of Cleaner Production. v. 14, 2006, pp. 1420-1430.

CONSELHO EMPRESARIAL BRASILEIRO PARA O DESENVOLVIMENTO SUSTENTÁVEL (CEBDS). Disponível em: $<$ http://www.cebds.org.br/cebds $>$. Acesso em: 10 jan 2011.

DANGELICO, R. M.; PONTRANDOLFO, P. From green product definitions and classifications to the Green Option Matrix. Journal of Cleaner Production, v. 18, 2010, pp. 1608-1628.

ECODESIGN. Disponível

em:

$<$ www.mma.gov.br/sitio/index.php?ido=conteudo.monta\&idEstrutura=133\&idConte udo=6656\&idMenu=6101 $>$. Acesso em: 10 jan 2011.

ECODESIGN Pilot: Product Investigation, Learning and Optimization Tool for Sustainable Product Development. Disponível 


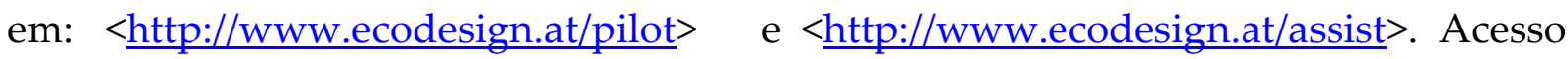
em: 15 jun 2011.

FARGNOLI, M.; KIMURA, F. Sustainable Design of Modern Industrial Products. 13th CIRP International Conference on Life Cycle Engineering, 2006.

FARGNOLI, M.; SAKAO, T. Coordinating ecodesign methods in early stages of industrial product design. International Journal of Environmentally Conscious Design \& Manufacturing. v. 14, n 2, 2008, pp. 35-65.

GIL, A. C. Como elaborar projetos de pesquisa. 4. ed. - São Paulo: Ed. Atlas, 2002.

HAIR JR., J. F. et al. Fundamentos de métodos de pesquisa em administração. Tradução Lene Belon Ribeiro - Porto Alegre: Bookman, 2005.

HEPPERLE C. et al. Calculating lifecycle interdependencies based on eco-design strategies, IEEE. International Conference on Industrial Engineering and Engineering Management. 2010, pp. 743-747.

JÖNBRINK, A.; MELIN, H. E (2008). How central authorities can support ecodesign: Company perspectives. Nordic Council of Ministers Copenhagen: TemaNord 2008:569. 2008.

KARLSSON, R.; LUTTROPP, C. EcoDesign: what's happening? An overview of the subject

area of EcoDesign and of the papers in this special issue. Journal of Cleaner Production, v. 14, 2006, pp. 1291-1298.

LUTTROPP, C.; LAGERSTEDT, J. EcoDesign and The Ten Golden Rules: generic advice for merging environmental aspects into product development. Journal of Cleaner Production, v. 14, 2006, pp. 1396-1408.

NASCIMENTO, L. F.; VENZKE, C. S. Ecodesign. In VILELA JR, A.; DEMAJOROVIC, $\mathrm{J}$ (orgs.). Modelos e ferramentas de gestão ambiental: desafios e perspectivas para as organizações. São Paulo: Ed. Senac, 2006, pp. 285-311.

UNITED NATIONS ENVIRONMENT PROGRAMME (UNEP). Disponível em: <http://www.unep.org>. Acesso em: 13 jan 2011.

VERGARA, S. C. Projetos e relatórios de pesquisa em administração. 3. ed. - São Paulo: Ed. Atlas, 2000.

VAN HEMEL, C.; CRAMER, J. Barriers and stimuli for ecodesign in SMEs. Journal of Cleaner Production, v. 10, 2002, pp. 439-453. 